\title{
Evaluation of the clinical profile, laboratory parameters and outcome of two hundred COVID-19 patients from a tertiary centre in India
}

\author{
Nitesh Gupta ${ }^{1}$, Pranav Ish ${ }^{1}$, Rohit Kumar ${ }^{1}$, Nishanth Dev ${ }^{2}$, Siddharth Raj Yadav ${ }^{1}$, Nipun Malhotra ${ }^{1}$,

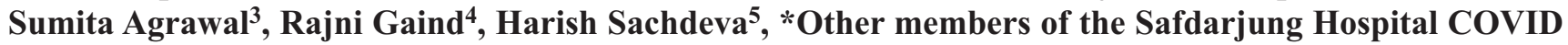 \\ 2019 working group \\ ${ }^{1}$ Department of Pulmonary Medicine, Safdarjung Hospital, New Delhi; ${ }^{2}$ Department of Medicine, Safdarjung Hospital, \\ New Delhi; ${ }^{3}$ Department of Pulmonary Medicine, Medipulse Hospital, Jodhpur; ${ }^{4}$ Department of Microbiology, \\ Safdarjung Hospital, New Delhi; ${ }^{5}$ Department of Anaesthesiology, Safdarjung Hospital, New Delhi, India \\ *Other members of the Safdarjung Hospital COVID-19 working group: Balvinder Singh (Microbiology), MK Sen \\ (Pulmonary Medicine), Shibdas Chakrabarti (Pulmonary Medicine), NK Gupta (Pulmonary medicine), AJ Mahendran \\ (Pulmonary Medicine), Ramesh Meena (Medicine), G Usha (Anaesthesiology), Santvana Kohli (Anaesthesiology), Sahil \\ Diwan (Anaesthesiology), Rushika Saksena (Microbiology), Vikramjeet Dutta (Microbiology), Anupam Kr Anveshi \\ (Microbiology)
}

Correspondence: Nitesh Gupta, Department of Pulmonary Medicine, and Nodal Officer for COVID-19, Safdarjung Hospital, New Delhi110029, India.

E-mail: niteshgupta2107@gmail.com

Key words: COVID-19; SARS-CoV-2; epidemiology; organ dysfunction scores; treatment outcome; prognosis.

Ethics approval: The present study was a prospective observational analysis promoted by the Safdarjung Hospital, New Delhi.

Patient consent for publication: The authors certify that they have obtained written informed consent from the patients to publish their personal details and follow up. The patient understands that their name and initials will not be published but anonymity cannot be guaranteed.

Funding: None.

Conflicts of interest: The authors declare no conflicts of interest.

Contributions: All the authors contributed to substantially to one or more of the following: conception or design of the work; the acquisition, analysis, or interpretation of data for the work; drafting the work or revising it critically for important intellectual content. All authors gave their final approval of the version to be published; are in agreement to be accountable for all aspects of the work in ensuring that questions related to the accuracy or integrity of any part of the work are appropriately investigated and resolved.

Received for publication: 14 July 2020.

Accepted for publication: 10 September 2020.

${ }^{\text {CC}}$ Copyright: the Author(s), 2020

Licensee PAGEPress, Italy

Monaldi Archives for Chest Disease 2020; 90:1507

doi: 10.4081/monaldi.2020.1507

This article is distributed under the terms of the Creative Commons Attribution Noncommercial License (by-nc 4.0) which permits any noncommercial use, distribution, and reproduction in any medium, provided the original author(s) and source are credited.

\section{Abstract}

COVID-19 is a pandemic with over 5 million cases worldwide. The disease has imposed a huge burden on health resources. Evaluation of clinical and epidemiological profiles of such patients can help in understanding and managing the outbreak more efficiently. This study was a prospective observational analysis of 200 diagnosed COVID-19 patients admitted to a tertiary care centre from $20^{\text {th }}$ march to $8^{\text {th }}$ May 2020 . All these patients were positive for COVID-19 by an oro-nasopharyngeal swabrtPCR based testing. Analyses of demographic factors, clinical characteristics, comorbidities, laboratory parameters, and the outcomes were performed. The mean age of the population was 40 years with a slight male predominance (116 patients out of 200, $58 \%)$. A majority of the patients $(147,73.5 \%)$ were symptomatic, with fever being the most common symptom (109, 54.5\%), followed by cough $(91,45.5 \%)$. An older age, presence of symptoms and their duration, leucocytosis, a high quick SOFA score, a high modified SOFA score, need for ventilator support, an AST level more than 3 times the upper limit of normal (ULN), and a serum creatinine level of $2 \mathrm{mg} / \mathrm{dl}$ or greater were at a significantly higher risk of ICU admission and mortality. Presence of diabetes mellitus, AST $>$ three times ULN, serum creatinine $2 \mathrm{mg} / \mathrm{dl}$ or higher, and a qSOFA score of 1 or higher were all associated with significantly greater odds of critical care requirement. Triage and severity assessment helps in deciding the requirement for a hospital stay and ICU admission for COVID-19 which can easily be done using clinical and laboratory parameters. A mild, moderate and severe category approach with defined criteria and treatment guidelines will help in judicious utilization of health-care resources, especially for developing countries like India.

\section{Introduction}

COVID-19 was first detected in India on 30 January 2020. Within a month, the numbers crossed a few hundred [1], and in a few months, the numbers crossed thousands. Our centre, a tertiary 
care hospital, was one of the first nodal centres for the care and management of such patients. The data for the first 21 patients admitted at the centre was suggestive of a mild self-limiting infection in all patients [2]. Subsequently however, a diverse pattern of clinical presentation and progression has emerged. A bigger spectrum of patient characteristics was observed: both extremes of ages, comorbidities, requirement of oxygen supplementation and/or invasive mechanical ventilation, and mortality. A review of the clinical profiles and outcomes of the subsequent two hundred patients is reviewed here. It is imperative to study these patients' clinical characteristics, since understanding the disease and its presentations can help in evaluating patients objectively and ensure judicious triage.

\section{Aims and objectives}

This study was conducted to evaluate the demographic, clinical, laboratory profile and outcomes of the COVID-19 confirmed patients admitted to a tertiary care centre in New Delhi, India.

\section{Methods}

The present study was a prospective observational analysis. Oro-nasopharyngeal swab-based testing using rt-PCR was employed for laboratory confirmation of COVID-19. A case was labelled as confirmed positive if rtPCR testing showed a positive result, irrespective of clinical signs or symptoms. The enrolment period was $20^{\text {th }}$ March 2020 to $8^{\text {th }}$ May 2020 (50 days). All patients were admitted and treated in accordance with the prevailing India guidelines for management of COVID-19. In the study period, initially all COVID-19 patients had to be admitted to a healthcare facility, even if asymptomatic. Eventually, patients with asymptomatic illness or mild disease were advised home isolation as per subsequent national guidelines released on $10^{\text {th }}$ May $2020[3,4]$.

The following clinical severity and assessment parameters were used to classify the patient [4].

Mild: Patients with uncomplicated upper respiratory tract infection, with or without mild symptoms such as fever, cough, sore throat, nasal congestion, malaise, headache, and without evidence of breathlessness or hypoxia (normal oxy-haemoglobin saturation $\left(\mathrm{SpO}_{2}\right)$.

Moderate: Clinical features of dyspnoea and/or hypoxia, fever, cough, $\mathrm{SpO}_{2}<94 \%$ (range $90-94 \%$ ) at room air, or a respiratory rate of 24 per min or higher. Radiological evidence of pneumonia with no signs of severe disease was also included.

Severe: Clinical signs of pneumonia plus one of the following: respiratory rate $>30$ breaths/min, severe respiratory distress, $\mathrm{SpO}_{2}$ $<90 \%$ at room air. The severe category had sub-classifications as follow: Acute respiratory distress syndrome - the patients were classified as ARDS as per Berlin Definition [5]; Sepsis and septic shock - the patients were classified as ARDS as per Surviving Sepsis Campaign guidelines [6].

An analysis of the demographic factors, clinical characteristics, comorbidities, laboratory parameters, and the outcome was performed. The primary analysis was performed on clinical characteristics, values of laboratory parameters, and comorbidities. The secondary analysis was performed in context of the need for critical care and the occurrence of death.

All of the data obtained thereby, were recorded systematically and analysed using standardized statistical methods. The statistical analysis was carried out using Statistical Package for Social Sciences 2015 (released 2015, IBM SPSS Statistics for Windows, ver. 23.0.; IBM Corp., Armonk, NY, USA) All quantitative data like age, weight, duration of symptoms, hemodynamic parameters, laboratory values, qSOFA score, mSOFA score and days to first negative report were estimated using measures of central location (mean). Qualitative variables were described as proportions. For normally distributed data, means were compared using unpaired $t$ test. Patients were analysed for clinical profile, and laboratory data in groups of Intensive Care Unit (ICU) and non-ICU, and also in Discharged and Died groups. Odds ratios were calculated for parameters that were significantly different among the groups. A predetermined $\mathrm{p}$-value of $<0.05$ was used to indicate statistical significance.

\section{Results}

A total of 200 COVID-19 positive patients were admitted during the duration of the study. Eighty-nine patients were discharged, 19 died, and 92 were currently admitted and undergoing treatment.

The demographic, clinical and laboratory characteristics are summarized in Table 1. The mean age of the population was 40 years with a slight male predominance $(116,58 \%)$. A majority of the patients were symptomatic $(147,73.5 \%)$, with fever being their most common symptom (80 patients among the symptomatic, $54.5 \%$ ) followed by cough $(69,47 \%)$. Sore throat (49 patients) and myalgia (40) were the next most frequent, whereas diarrhoea (4) was uncommon. The presentation was acute with short mean durations of symptoms: 3 days for breathlessness, sore throat and cough, and 4 days for fever.

Nearly half of the patients $(83,41.5 \%)$ had pre-existing comorbidities. The frequencies as recorded in decreasing order were systemic hypertension (46), diabetes mellitus (DM) (32), active tuberculosis (TB) (11), and coronary artery disease (9). Notably, chronic kidney disease (4) and obstructive airway disease (1) were seen very infrequently.

\section{Comparison between ICU and non-ICU patients}

Thirty-two (16\%) patients required admission to the Intensive Care Unit. Mortality was seen in 18 ICU patients, representing $56.25 \%$ of all patients requiring ICU and $85.71 \%$ of ICU requiring patients with an endpoint of either discharge or death. This was significantly higher than mortality in the non-ICU group, where only 1 out of the 87 outcome-established patients (1.2\%) died.

The overall vitals including oxygen saturation and laboratory haemoglobin, leucocyte, platelet count and organ functions showed significant differences among non-ICU and ICU patients. (Table 2). The patients admitted to ICU as compared to non-ICU patients were older (51 vs 37.9 years), had symptom duration for over a week at presentation (10.3 vs 3.8 days) and had a short duration of stay (4.2 vs 12.8 days) on account of mortality/shift out. ICU patients had anaemia, leucocytosis, hypoxia, tachypnoea with deranged organ function tests at admission. Regarding comorbidities, diabetes was statistically more prevalent in ICU patients $(p=0.01)$, whereas systemic hypertension, coronary artery disease and malignancy were slightly higher but falling short of statistical significance $(\mathrm{p}>0.5)$. 
Among patients requiring ICU care, the presenting characteristics at the time of hospitalization at our centre were assessed. A greater age was found to be associated with higher odds of needing critical care (odds ratio, OR: 1.05; 95\% Confidence Interval, CI: $1.02-1.07 ; \mathrm{p}<0.001)$. Further, patients with longer duration of disease and presenting late to the hospital were also found to be at a higher risk for the same (OR: 1.13, 95\% CI: 1.05-1.22, $\mathrm{p}=0.001$ ). Symptomatic patients required ICU; those with breathlessness had 48 times chances of admission compared to those without dyspnoea. In addition, the presence of comorbidities increases the odds of ICU admission by 2-3-fold (OR 2.78, 1.27-6.06, $\mathrm{p}=0.01$ ); patients with DM had 3.67 times need for ICU admission compared to non-diabetic patients. It was also observed that patients in the ICU had a shorter duration of breathlessness and sore throat prior to admission; this probably reflects the rapid progression of dyspnoea in this cohort of patients which required them to be shifted to the ICU shortly after admission.

The vitals at the time of admission predicted the need for ICU admission; a low $\mathrm{Spo}_{2}$ and a high respiratory rate increases the chances of ICU admission by 35 and $32 \%$, respectively; OR of 0.65 $(0.55-0.77, \mathrm{p}<0.001)$ and $1.32(1.21-1.45, \mathrm{p}<0.001)$, respectively.

Amongst the lab parameters, an increased TLC, low haemoglobin, increased urea, creatinine and deranged liver enzymes predicted the need for ICU admission. An elevated qSOFA score at emergency triage increases the chances of ICU admission by 13 times $(13.45,5.67-31.92), \mathrm{p}<0.001$.

Table 1. Epidemiological, clinical, laboratory, and outcome details of the patients in the study.

\begin{tabular}{lc} 
Parameter & Mean \pm SD (range) \\
Age (years) & $40.03 \pm 17.03(0-90)$ \\
Gender (male:female ratio) & $58: 42$ \\
\hline Resident of Delhi (\%) & 81 \\
Stay duration (days) & $11.17 \pm 5.43(1-27)$ \\
\hline Duration of symptoms at admission (days) & $4.31 \pm 5.48(0-30)$ \\
Duration spent outside India (days) & $1.07 \pm 3.88(0-36)$ \\
\hline Days with fever & $4.15 \pm 5.12(1-30)$ \\
Days with rhinorrhoea & $2.82 \pm 1.89(1-7)$ \\
\hline Days with breathlessness & $3.17 \pm 2.55(1-12)$ \\
Days with sore throat & $3.3 \pm 2.27(1-15)$ \\
\hline Days with cough & $3.52 \pm 3.65(1-30)$ \\
GCS score & $9.67 \pm 6.14(3-15)$ \\
\hline SpO $(\%)$ & $95.58 \pm 5.29(70-100)$ \\
Respiratory rate (/minute) & $19.78 \pm 4.43(12-35)$ \\
\hline Total leucocyte count (/mm $\left.{ }^{3}\right)$ & $7286.41 \pm 3521.83(588-19500)$ \\
Blood lymphocyte count $\left(/ \mathrm{mm}^{3}\right)$ & $2261.72 \pm 975.83(247-6634)$ \\
\hline Blood Hb (g/dL) & $13.04 \pm 2.26(6-18)$ \\
Blood platelet (/mm $\left.{ }^{3}\right)$ & $195000 \pm 82936.087(40000-537000)$ \\
\hline Blood urea (mg/dl) & $27.94 \pm 16.37(12-125)$ \\
Serum creatinine (mg/dl) & $0.75 \pm 0.66(0.1-6.9)$ \\
\hline AST (IU/l) & $63.67 \pm 85.87(13-489)$ \\
ALT (IU/l) & $59.1 \pm 108.75(10-1029)$ \\
\hline ALP (IU/l) & $111.88 \pm 74.67(16-427)$ \\
qSOFA score & $0.24 \pm 0.58(0-3)$ \\
\hline Days to first negative report & $10.83 \pm 4.26(3-20)$ \\
\hline
\end{tabular}

ICU, intensive care unit; AST, aspartate transaminase; ALT, alanine transaminase; ALP, Alkaline phosphatase; mSOFA, modified sequential organ failure assessment score; qSOFA, quick sepsis related organ failure score; HTN, hypertension; DM, diabetes mellitus; TB, tuberculosis; COPD, chronic obstructive pulmonary disease; BA, bronchial asthma; CAD, coronary artery disease; CKD, chronic kidney disease.

\begin{tabular}{|c|c|}
\hline Clinical and outcome profile & $\mathrm{n}=\mathbf{2 0 0}$ \\
\hline Symptom (any) & $147(73.5 \%)$ \\
\hline Fever & $109(54.5 \%)$ \\
\hline Cough & $91(45.5 \%)$ \\
\hline Sore throat & $66(33 \%)$ \\
\hline Myalgia & $54(27 \%)$ \\
\hline Breathlessness & $35(17.5 \%)$ \\
\hline Headache & $22(11 \%)$ \\
\hline Rhinorrhoea & $1(0.5 \%)$ \\
\hline Diarrhoea & $6(3 \%)$ \\
\hline Anosmia & $1(0.5 \%)$ \\
\hline Comorbid illness (any) & $83(41.5 \%)$ \\
\hline HTN & $46(23 \%)$ \\
\hline $\mathrm{DM}$ & $32(16 \%)$ \\
\hline Active TB & $11(5.5 \%)$ \\
\hline $\mathrm{CAD}$ & $9(4.5 \%)$ \\
\hline Hypothyroidism & $6(3 \%)$ \\
\hline CVA $(\%)$ & $5(2.5 \%)$ \\
\hline History of malignancy & $5(2.5 \%)$ \\
\hline CKD & $4(2 \%)$ \\
\hline COPD/BA & $1(0.5 \%)$ \\
\hline Anxiety disorder/depression & $1(0.5 \%)$ \\
\hline Required ICU & $32(16 \%)$ \\
\hline Need for critical care in males:females (\%:\%) & $17.2: 14.3(\mathrm{p}=0.7)$ \\
\hline Required mechanical ventilation & $21(10.5 \%)$ \\
\hline Serum creatinine $>2 \mathrm{mg} / \mathrm{dl}$ & $5(2.5 \%)$ \\
\hline Blood lymphopenia & $9(4.5 \%)$ \\
\hline AST $>120$ IU/l & $21(10.5 \%)$ \\
\hline ALT $>120$ IU/l & $13(6.5 \%)$ \\
\hline qSOFA score $>0$ & $36(18 \%)$ \\
\hline Antibiotic administered & $37(18.5 \%)$ \\
\hline $\begin{array}{l}\text { If days to first negative throat/nasopharyngeal } \\
\text { swab rtPCR }>14\end{array}$ & $46(23 \%)$ \\
\hline $\mathrm{qSOFA}=0$ & $164(82 \%)$ \\
\hline qSOFA $>0$ & $36(18 \%)$ \\
\hline $\mathrm{qSOFA}=1$ & $27(13.5 \%)$ \\
\hline $\mathrm{qSOFA}=2$ & $6(3 \%)$ \\
\hline $\mathrm{qSOFA}=3$ & $3(1.5 \%)$ \\
\hline
\end{tabular}


Table 2. Epidemiological, clinical, laboratory, and outcome details in patients who required critical care (ICU) vs patients not requiring critical care (non-ICU).

\begin{tabular}{|c|c|c|c|c|}
\hline Parameter & CU (mean $\pm \mathrm{SD})$ & non-ICU (mean \pm SD) & p-value & Odds ratio ( $95 \%$ CI, p-value) \\
\hline $\mathrm{N}$ & 32 & 168 & & \\
\hline Age (years) & $51.06 \pm 16.03$ & $37.93 \pm 16.44$ & $<0.001$ & $1.05(1.02-1.07, p<0.001)$ \\
\hline Duration of stay (days) & $4.29 \pm 4.73$ & $12.83 \pm 4.14$ & $<0.001$ & $0.64(0.54-0.77, \mathrm{p}<0.001)$ \\
\hline Duration of symptoms at admission (days & s) $5.15 \pm 7.07$ & $3.83 \pm 4.7$ & 0.31 & \\
\hline Duration of fever (days) & $5.07 \pm 7.64$ & $3.83 \pm 3.91$ & 0.27 & \\
\hline Duration of rhinorrhea (days) & $4 \pm 4.23$ & $2.56 \pm 1.33$ & 0.35 & \\
\hline Duration of breathlessness (days) & $2.42 \pm 1.86$ & $4.82 \pm 3.12$ & 0.008 & $0.66(0.46-0.94, p=0.02)$ \\
\hline Duration of sore throat (days) & $1.82 \pm .80$ & $4.05 \pm 2.41$ & $<0.001$ & $0.32(0.17-0.59, \mathrm{p}<0.001)$ \\
\hline Duration of cough (days) & $2.86 \pm 2.68$ & $3.82 \pm 4.01$ & 0.18 & \\
\hline $\mathrm{SpO}_{2}(\%)$ & $86.84 \pm 8.48$ & $97.24 \pm 1.59$ & $<0.001$ & $0.65(0.55-0.77, \mathrm{p}<0.001)$ \\
\hline Respiratory rate (/minute) & $25.25 \pm 6.79$ & $18.74 \pm 2.82$ & $<0.001$ & $1.32(1.21-1.45, \mathrm{p}<0.001)$ \\
\hline Total leucocyte count $\left(/ \mathrm{mm}^{3}\right)$ & $11,800 \pm 5179$ & $6530 \pm 2481$ & $<0.001$ & $1.00(1.00-1.00, p<0.001)$ \\
\hline Blood lymphocyte count (/mm³) & $2511 \pm 1380$ & $2220 \pm 891$ & 0.2 & \\
\hline Blood hemoglobin (g/dl) & $10.83 \pm 1.72$ & $13.48 \pm 2.09$ & $<0.001$ & $0.55(0.43-0.70, \mathrm{p}<0.001)$ \\
\hline Blood platelet $\left(/ \mathrm{mm}^{3}\right)$ & $211,000 \pm 93,529$ & $192,000 \pm 7038$ & 0.26 & \\
\hline Blood urea (mg/dl) & $45.26 \pm 26.14$ & $24.47 \pm 10.81$ & $<0.001$ & 1.07 (1.04-1.11, p<0.001) \\
\hline Serum creatinine (mg/dl) & $1.14 \pm 1.37$ & $0.67 \pm 0.34$ & 0.001 & $2.58(1.14-5.84, p=0.02)$ \\
\hline AST (IU/l) & $118.11 \pm 142.77$ & $41.73 \pm 25.67$ & $<0.001$ & $1.02(1.00-1.03, p=0.01)$ \\
\hline ALT (IU/l) & $96.15 \pm 190.88$ & $44.16 \pm 39.02$ & 0.17 & \\
\hline $\operatorname{ALP}(I U / 1)$ & $162.74 \pm 92.67$ & $91.08 \pm 54.25$ & $<0.001$ & $1.01(1.01-1.02, p=0.001)$ \\
\hline mSOFA score & $6.71 \pm 3.9$ & & $<0.001$ & \\
\hline qSOFA score & $1.03 \pm 0.97$ & $0.09 \pm 0.29$ & $<0.001$ & $13.45(5.67-31.92, \mathrm{p}<0.001)$ \\
\hline Discharged (N) & 3 & 86 & & \\
\hline $\operatorname{Died}(\mathrm{N})$ & 18 & 1 & $<0.001$ & \\
\hline \multirow[t]{2}{*}{ Still admitted (N) } & 11 & 81 & & \\
\hline & ICU $(n=32)(\%)$ & Non-ICU ( $n=168)(\%)$ & p-value & \\
\hline Males/females (\%) & $20(62.4) / 12(37.6)$ & $96(57.1) / 72(42.9)$ & 0.7 & \\
\hline Fever (\%) & $28(87.5)$ & $81(48.2)$ & $<0.001$ & $7.52(2.52-22.37, p<0.001)$ \\
\hline Rhinorrhoea (\%) & $2(6.25)$ & $9(5.38)$ & 0.69 & \\
\hline Weakness (\%) & $20(62.5)$ & $33(19.65)$ & $<0.001$ & $7.81(3.43-17.78, p<0.001)$ \\
\hline Headache (\%) & $13(40.625)$ & $9(5.36)$ & $<0.001$ & $12.09(4.56-32.01, \mathrm{p}<0.001)$ \\
\hline Breathlessness (\%) & $24(75)$ & $11(6.55)$ & $<0.001$ & $42.82(15.64-117.20, p<0.001)$ \\
\hline Sore throat (\%) & $22(68.75)$ & $44(26.19)$ & $<0.001$ & $6.2(2.72-14.11, \mathrm{p}<0.001)$ \\
\hline Diarrhoea (\%) & $0(0)$ & $6(3.57)$ & 0.59 & \\
\hline Cough (\%) & $29(90.62)$ & $62(36.9)$ & $<0.001$ & $16.53(4.83-56.50, \mathrm{p}<0.001)$ \\
\hline Comorbidities (any) (\%) & $20(62.5)$ & $63(37.5)$ & 0.01 & $2.78(1.27-6.06, p=0.01)$ \\
\hline HTN (\%) & $11(34.38)$ & $35(20.83)$ & 0.11 & \\
\hline DM (\%) & $11(34.38)$ & $21(12.5)$ & 0.01 & $3.67(1.55-8.67, p=0.003)$ \\
\hline Post TB (\%) & $0(0)$ & $4(2.38)$ & 0.38 & \\
\hline COPD/BA (\%) & $0(0)$ & $1(0.6)$ & 0.66 & \\
\hline Anxiety disorder/depression (\%) & $0(0)$ & $1(0.6)$ & 0.66 & \\
\hline Cad (\%) & $3(9.38)$ & $6(3.57)$ & 0.15 & \\
\hline Hypothyroidism (\%) & $0(0)$ & $6(3.57)$ & 0.28 & \\
\hline History of malignancy (\%) & $1(3.125)$ & $4(2.38)$ & 0.8 & \\
\hline Active TB (\%) & $2(6.25)$ & $8(4.88)$ & 0.68 & \\
\hline CKD (\%) & $1(3.125)$ & $4(2.43)$ & 1 & \\
\hline Serum creatinine $>2$ mg/dl (\%) & $4(12.5)$ & $1(0.6)$ & 0.002 & $16.75(1.67-167.82, p=0.017)$ \\
\hline AST >120 IU/1 (\%) & $9(28.125)$ & $5(2.98)$ & $<0.001$ & $13.68(2.68-69.96, p=0.002)$ \\
\hline ALT > 120 IU/l (\%) & $4(12.5)$ & $8(4.88)$ & 0.23 & \\
\hline
\end{tabular}

Odds ratio was calculated only if the difference between the two groups (ICU and non-ICU) was significant. Some range values may appear as 1.00-1.00 due to rounding. CI, confidence interval; AST, aspartate transaminase; ALT, alanine transaminase; ALP, alkaline phosphatase; mSOFA, modified sequential organ failure assessment score; qSOFA, quick sepsis related organ failure score; HTN, hypertension; DM, diabetes mellitus; TB, tuberculosis; COPD, chronic obstructive pulmonary disease; BA, bronchial asthma; CAD, coronary artery disease; CKD, chronic kidney disease. 


\section{Comparison between outcome groups: Discharged versus Died}

On subgroup analysis of the cohort based on final outcome, i.e. discharged $(n=89)$ and died $(n=19)$; mean age, history and mean duration of symptoms were significantly different in the two groups. The prevalence of diabetes mellitus was significantly higher in the latter group, whereas other comorbid illnesses did not have a significant impact on outcomes. The latter group also had significantly higher total blood leukocytes, although no difference was noted in the lymphocyte counts between the two groups. Deranged liver and kidney function tests with high quick SOFA and modified SOFA scores were noted in the mortality group. Patients requiring mechanical ventilation, having high quick SOFA score (1 or higher), having AST more than 3 times upper limit of normal (ULN) and having serum creatinine more than $2 \mathrm{mg} \%$ were at a significantly higher risk of mortality as evident in Table 3.

\section{Discussion}

This was a prospective observational study of 200 COVID-19 patients admitted to a tertiary care centre in New Delhi, India. The results are a way forward from the original 21 patient data [2]. The cohort was constituted by a young population with comorbidities reported in nearly half. The age distribution of the cohort is represented in Figure 1. The mean age is slightly lower than those reported in studies from China and the USA [7-10] but is congruent with the relatively younger population in India [11]. The disease was slightly more common in men (58\%) than women. A series of 5700 COVID-19 cases from USA also revealed a slight male preponderance [10]. A similar finding was also observed by Guan and colleagues [7]. A hypothesis put forward for this is the slightly larger male population working in areas that involve potential exposure to the disease. The most common symptom was fever (54.5\%), similar to the findings of Guan and colleagues (Figure 1) [7].

The study found the need for ICU care in $16 \%$ patients, similar to a study from New York, USA [10] (14.2\%) but higher than the $5 \%$ reported from Wuhan [8]. The age distribution of patients needing ICU care is depicted in Figure 1.

The prevalence of comorbidities is represented in Figure 2. Except for DM, none of the comorbid illnesses were risk factors associated with significantly higher need for ICU care or higher mortality. Among patients who did not survive, comorbid illness was prevalent in $63 \%$. This is in agreement with a multicentre study that found at least one comorbidity in $74 \%$ of patients who died [12]. Further DM was a risk factor for both need for critical care (OR: 3.67, 95\%; CI: 1.55-8.67, $\mathrm{p}=0.003$ ), and for mortality (OR: 3.90, 95\% CI: 1.33-11.41, p=0.01). In a meta-analysis of 523 studies, Zheng and colleagues also found DM to be a risk factor for both critical and mortal patients [13].

In the present study, a serum creatinine value of $2 \mathrm{~g} / \mathrm{dl}$ or higher was also found to be a risk factor for need for critical care with an odds ratio of 16.75 (95\% CI: 1.67-167.82, $\mathrm{p}=0.017)$. Zheng and colleagues also found a higher risk for critical care cases in values higher than $1.5 \mathrm{~g} / \mathrm{dL}$ [13]. Further, serum aspartate aminotransferase values of $120 \mathrm{IU} / 1$ or higher were also associated with a necessity of critical care (OR: 13.68, 95\% CI: 2.68-69.96, $\mathrm{p}=0.002$ ). However, serum alanine aminotransferase was not associated with greater need of critical care. Further, a qSOFA score of
1 or higher was found to be a risk factor for mortality (OR: 80, 95\% CI: 9.06-706.20, $<<0.001)$. A representation of the frequency of qSOFA $>0$ in patients who died versus those who survived and were discharged is illustrated in Figure 3. The Surviving Sepsis guidelines [6] recommends using a cut-off of 2 or higher as a predictor of poor outcomes in patients with pneumonia. However, a cut-off of 1 or higher may be a better predictor of worse prognosis in COVID-19 [14].

\section{Age Distribution}
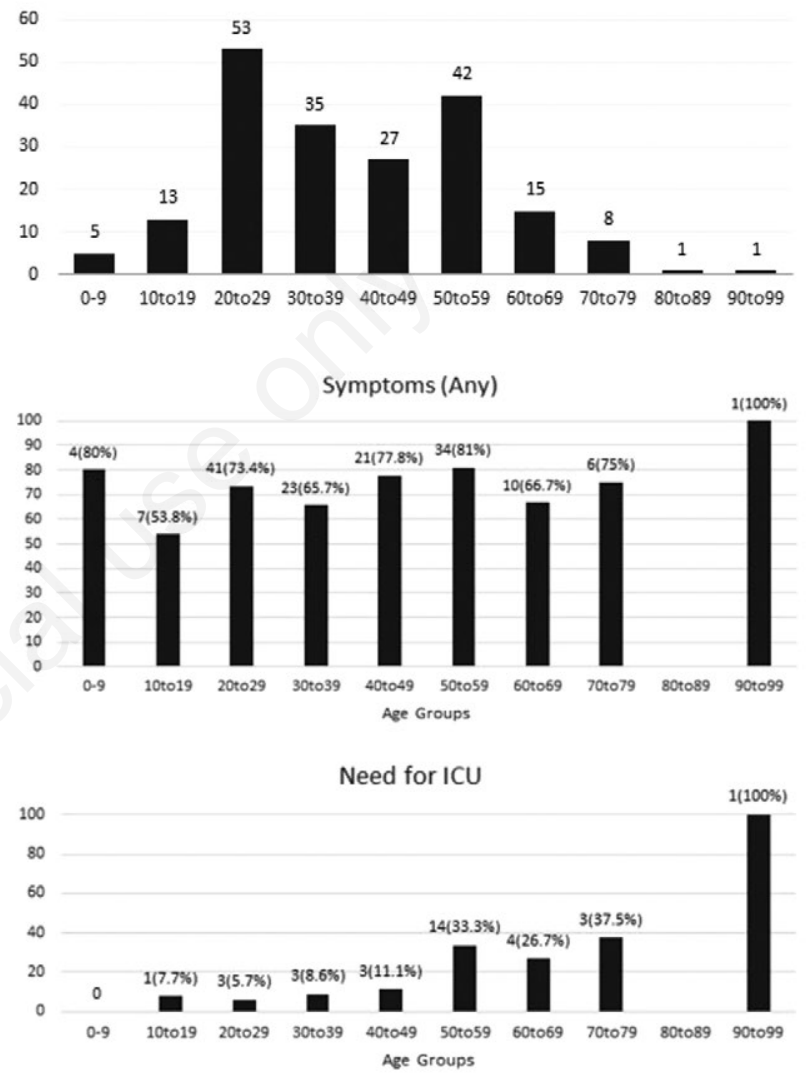

Figure 1. Age distribution, frequency of symptomatic patients and need for critical care in each age group.

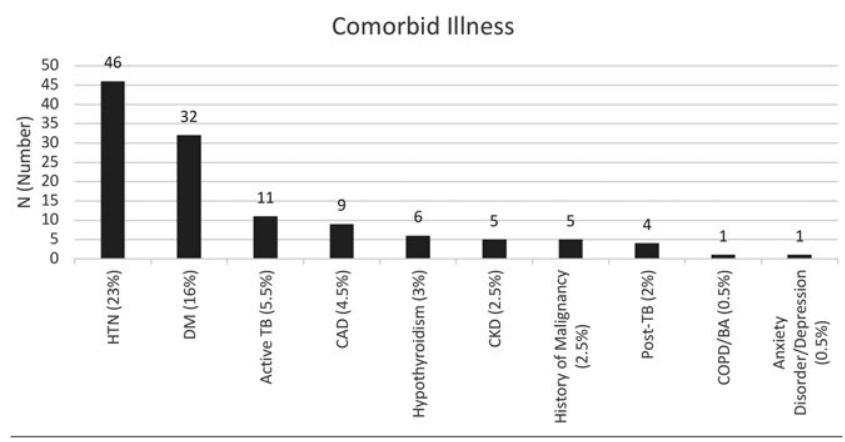

Figure 2. Prevalence of comorbid illnesses in the full cohort of 200 patients. HTN, hypertension; DM, diabetes mellitus; TB, tuberculosis; $\mathrm{CAD}$, coronary artery disease; $\mathrm{CKD}$, chronic kidney disease; COPD, chronic obstructive pulmonary disease; BA, bronchial asthma. 
A study from 8 countries in Europe has shown that Tuberculosis may not be a major determinant of mortality. Our study also did not find any significant correlation of TB with mortality, however the number of patients with TB and COVID-19 was very small. Larger studies can determine the prognosis and association, which is particularly relevant to a high TB and COVID-19 burdened country like India [15].

A majority of patients in this study were stable, requiring only symptomatic care. On the other end, among those requiring critical care, a very high incidence of mortality was observed. Further, mortality occurred over a relatively short duration of stay. This further necessitates the importance of triage, and early identification of severe or critical cases. Patients with severe COVID-19 or those who are likely to deteriorate into organ failure, require critical care with or without ventilatory support, whereas mild COVID-19 can be managed with home isolation, and regular and diligent followup. The intermediate category of moderate COVID-19 may acutely worsen and slip into the severe category. As such these patients should be hospitalized for close observation in addition to usual treatment. This risk stratification is akin to Influenza management guidelines, which recommend a risk-category based approach to identify the need for hospitalization and the treatment required.

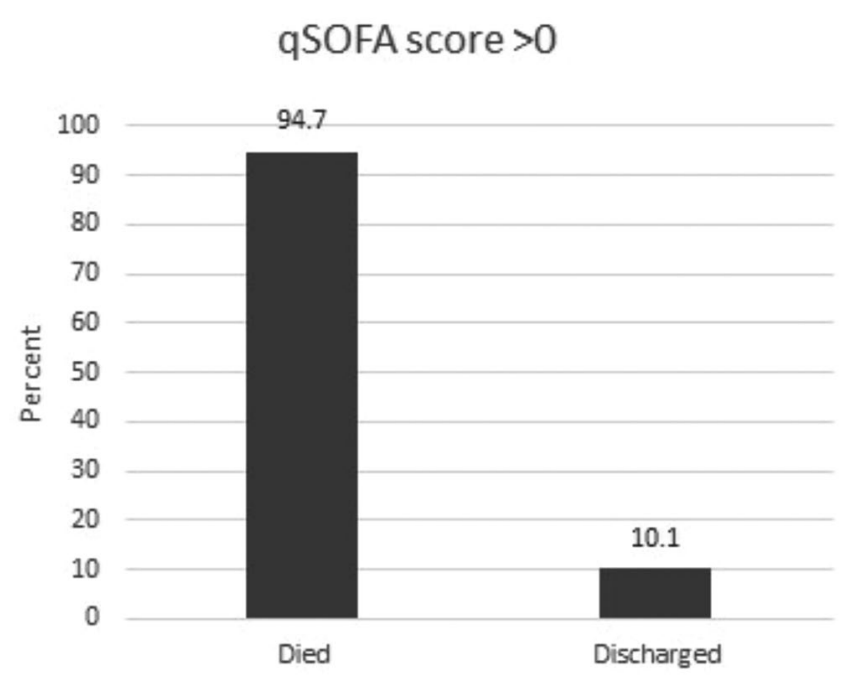

Figure 3. Percentage of patients with quick sepsis related organ failure (qSOFA) score $>0$, in patients who died versus those who survived and were discharged.

Table 3. Epidemiological, clinical, laboratory, and outcome details in patients who were discharged versus those who died.

\begin{tabular}{|c|c|c|c|c|}
\hline Parameter & Discharged (mean \pm SD) & Died (mean \pm SD) & p-value & Odds ratio ( $95 \% \mathrm{CI}$, p value) \\
\hline $\mathrm{N}$ & 89 & 19 & & \\
\hline Age (years) & $41.34( \pm 16.25)$ & $52.68( \pm 11.55)$ & 0.001 & $1.05(1.01-1.08, p=0.01)$ \\
\hline Stay duration (days) & $12.98( \pm 4.05)$ & $2.68( \pm 1.7)$ & $<0.001$ & $0.38(0.22-0.63, \mathrm{p}<0.001)$ \\
\hline Duration of symptoms at admissic & on (days) $4.4( \pm 5.44)$ & $4.75( \pm 2.63)$ & 0.82 & \\
\hline Duration abroad (days) & $2.4( \pm 5.54)$ & $0( \pm 0)$ & $<0.001$ & 1 \\
\hline Days with fever & $4.77( \pm 5.04)$ & $2.05( \pm 1.31)$ & 0.004 & $0.57(0.38-0.87, p=0.01)$ \\
\hline Days with rhinorrhoea & $2.8( \pm 1.64)$ & $7( \pm 0)$ & $*$ & \\
\hline Days with breathlessness & $3.78( \pm 2.17)$ & $1.94( \pm 1.35)$ & 0.04 & $0.54(0.30-0.97, p=0.04)$ \\
\hline Days with sore throat & $3.7( \pm 1.9)$ & $2( \pm 0.82)$ & $<0.001$ & $0.44(0.24-0.79, p=0.01)$ \\
\hline Spo2 (\%) & $96.8( \pm 3.38)$ & $82.26( \pm 4.65)$ & $<0.001$ & $0.67(0.57-0.78, \mathrm{p}<0.001)$ \\
\hline Respiratory rate (/minute) & $18.76( \pm 2.44)$ & $29.89( \pm 3.8)$ & $<0.001$ & $2.25(1.50-3.37, \mathrm{p}<0.001)$ \\
\hline Total leucocyte count $\left(/ \mathrm{mm}^{3}\right)$ & $6669( \pm 2565)$ & $14001( \pm 5270)$ & $<0.001$ & $1.00(1.00-1.00, p<0.001)$ \\
\hline Blood lymphocyte count $\left(/ \mathrm{mm}^{3}\right)$ & $2204( \pm 956)$ & $2551( \pm 1137)$ & 0.31 & \\
\hline Blood Hb (g/dL) & $13.82( \pm 1.71)$ & $10.58( \pm 1.87)$ & $<0.001$ & $0.21(0.98-0.46, p<0.001)$ \\
\hline Blood platelet count $\left(/ \mathrm{mm}^{3}\right)$ & $199000( \pm 81000)$ & $218000( \pm 94669)$ & 0.44 & \\
\hline Blood urea (mg/dL) & $23.52( \pm 7.74)$ & $54.83( \pm 26.62)$ & $<0.001$ & $1.16(1.09-1.24, \mathrm{p}<0.001)$ \\
\hline Serum creatinine $(\mathrm{mg} / \mathrm{dL})$ & $0.68( \pm 0.25)$ & $1.38( \pm 1.63)$ & $<0.001$ & $5.29(1.22-22.96, p=0.03)$ \\
\hline AST (IU/l) & $40.68( \pm 20.81)$ & $157.11( \pm 162.16)$ & 0.007 & $1.02(1.00-1.05, p=0.7)$ \\
\hline ALT (IU/l) & $43.63( \pm 20.99)$ & $125.33( \pm 229.68)$ & 0.15 & $1.04(1.0-1.08, p=0.06)$ \\
\hline ALP (IU/I) & $94.17( \pm 54.65)$ & $191.33( \pm 90.15)$ & 0.001 & $1.02(1.00-1.03, p=0.005)$ \\
\hline po2 (mmHg) & - & $82.73( \pm 92.47)$ & & \\
\hline pco2 (mmHg) & - & $41.47( \pm 20.64)$ & & \\
\hline fio2 & - & $0.48 \pm 0.32$ & & \\
\hline hco3- (mEq/l) & - & $21.79( \pm 3.72)$ & & \\
\hline $\mathrm{pH}$ & - & $7.31( \pm 0.14)$ & & \\
\hline mSOFA score & - & $7.83( \pm 2.92)$ & & \\
\hline qSOFA score & $0.1( \pm 0.303)$ & $1.58( \pm 0.84)$ & $<0.001$ & $88.27(10.60-735.03, p<0.001)$ \\
\hline Male/female (\% rate) & $80.95 / 84.44$ & 19.05/15.56 & 0.8 & \\
\hline Delhi/elsewhere (\%rate) & $79.74 / 89.66$ & $20.26 / 10.34$ & 0.27 & \\
\hline
\end{tabular}

To be continued on next page 
This study has its limitations. It is representative of only diagnosed cases of COVID-19. The symptom, comorbidity, and outcome profile of undiagnosed COVID-19 cases, who have not undergone testing, might change the overall statistics. This study used rt-PCR based assessment before discharge, in accordance with national guidelines prevalent at the time. As such, conversion before discharge does not connote true infectivity status conversion. Viral culture is more accurate in this regard but is not practical in large numbers such as those of an outbreak. Long term follow-up study is required to understand the true impact of the disease on human physiology, and to study the possibility of re-infection.

\section{Conclusions}

This observational study provides insights into the epidemiological and clinical profile, and outcomes of COVID-19 patients admitted in a tertiary care hospital in New Delhi, India. The wide variations between outcome groups support the need for further indepth investigatory studies to stratify 'risk' at admission and during hospital stay.

\section{References}

1. Ministry of Health and Family Welfare, Government of India. COVID-19 India. Accessed on: $8^{\text {th }}$ May 2020. Available from: https://www.mohfw.gov.in/

2. Gupta N, Agrawal S, Ish P, et al. Clinical and Epidemiologic profile of the initial COVID-19 patients at a tertiary care centre in India. Monaldi Arch Chest Dis 2020;90:1294. doi: 10.4081/monaldi.2020.1294.

3. Ministry of Health and Family Welfare, Government of India. Revised guidelines for home isolation of very mild/pre-symptomatic COVID-19 cases. Available from: https://www.mohfw. gov.in/pdf/RevisedguidelinesforHomeIsolationofverymildpresy mptomaticCOVID19cases10May2020.pdf

4. Ministry of Health \& Family Welfare, Government of India. Revised guidelines on clinical management of COVID-19. Accessed on: $20^{\text {th }}$ June 2020. Available from: https://www. mohfw.gov.in/pdf/RevisedNationalClinicalManagementGuide lineforCOVID1931032020.pdf

5. ARDS Definition Task Force, Ranieri VM, Rubenfeld GD, et al. Acute respiratory distress syndrome: The Berlin Definition. JAMA 2012;307:2526-33.

Table 3. Continued from previous page.

\begin{tabular}{|c|c|c|c|c|}
\hline Disc & irged $(n=89)(\%)$ & Died (n=19) (\%) & p-value & \\
\hline History of contact & $53(59.55)$ & $14(73.68)$ & 1 & \\
\hline History of travel (\%) & $29(32.58)$ & $0(0)$ & 0.002 & 1 \\
\hline History of symptoms (\%) & $60(67.42)$ & $19(100)$ & 0.002 & 1 \\
\hline History of fever (\%) & $35(39.32)$ & $19(100)$ & $<0.001$ & 1 \\
\hline History of rhinorrhoea (\%) & $5(5.61)$ & $1(5.26)$ & 0.95 & \\
\hline History of weakness (\%) & $9(10.11)$ & $18(94.74)$ & $<0.001$ & $160(19.05-1344.11, p<0.001)$ \\
\hline History of headache (\%) & $9(10.11)$ & $10(52.63)$ & $<0.001$ & $9.88(3.18-30.70, p<0.001)$ \\
\hline History of breathlessness (\%) & $9(10.11)$ & $18(94.74)$ & $<0.001$ & $160(19.05-1344.11, p<0.001)$ \\
\hline History of sore throat (\%) & $30(33.71)$ & $16(84.21)$ & $<0.001$ & $10.49(2.83-38.84, \mathrm{p}<0.001)$ \\
\hline History of diarrhoea (\%) & $3(3.37)$ & $0(0)$ & 0.42 & \\
\hline History of cough (\%) & $38(42.7)$ & $19(100)$ & $<0.001$ & 1 \\
\hline Comorbid illness (any) (\%) & $39(43.82)$ & $12(63.16)$ & 0.14 & \\
\hline Post TB (\%) & $3(3.37)$ & $0(0)$ & 1 & \\
\hline $\mathrm{DM}(\%)$ & $14(15.73)$ & $8(42.1)$ & 0.023 & $3.90(1.33-11.41, p=0.01)$ \\
\hline HTN (\%) & $27(30.34)$ & $8(42.1)$ & 0.418 & \\
\hline COPD/BA (\%) & $0(0)$ & $0(0)$ & & \\
\hline Anxiety disorder/depression (\%) & $1(1.12)$ & $0(0)$ & 0.64 & \\
\hline CAD $(\%)$ & $5(5.62)$ & $1(5.26)$ & 0.95 & \\
\hline Hypothyroidism (\%) & $5(5.62)$ & $0(0)$ & 0.29 & \\
\hline History of malignancy (\%) & $1(1.12)$ & $1(5.26)$ & 0.22 & \\
\hline If days to first negative throat/nasophary & eal swab rt-PCR >14 (\%) & $21(23.59)$ & - & \\
\hline Required ICU (\%) & $3(3.37)$ & $18(94.73)$ & $<0.001$ & $516(50.74-5247.96, p<0.001)$ \\
\hline Required mechanical ventilation (\%) & $1(1.12)$ & 18(94.73) & $<0.001$ & $1584(94.62-26516.08, \mathrm{p}<0.001)$ \\
\hline Lymphopenia (\%) & $6(6.74)$ & $0(0)$ & 0.32 & \\
\hline Serum creatinine $>2$ mg/dL (\%) & $0(0)$ & $3(15.78)$ & $<0.001$ & 1 \\
\hline AST > 120 IU/l (ALT known in $n=37)(\%)$ & $0(0)$ & $8(42.10)$ & $<0.001$ & 1 \\
\hline ALT >120 IU/ (ALT known in $n=37)(\%)$ & $0(0)$ & $3(15.78)$ & 0.06 & \\
\hline qSOFA $>0(\%)$ & $9(10.11)$ & 18(94.74) & $<0.001$ & $80(9.06-706.20, p<0.001)$ \\
\hline
\end{tabular}

* Only one patient had rhinorrhoea in the group with the outcome = death, hence application of a test of significance was avoided. Odds ratio was calculated only if the difference between the two groups (ICU and non-ICU) was significant. CI, confidence interval; po2, partial pressure of oxygen in arterial blood; $\mathrm{pco}_{2}$, partial pressure of carbon dioxide in arterial blood; fio 2 , fractional inhaled oxygen; hco3-, concentration of bicarbonate in arterial blood; rtPCR, reverse transcriptase polymerase chain reaction; AST, aspartate transaminase; ALT, alanine transaminase; ALP, alkaline phosphatase; mSOFA, modified sequential organ failure assessment score; qSOFA, quick sepsis related organ failure score; HTN, Hypertension; DM, diabetes mellitus; TB, tuberculosis; COPD, chronic obstructive pulmonary disease; BA, bronchial asthma; CAD, coronary artery disease; CKD, chronic kidney disease. 
6. Rhodes A, Evans LE, Alhazzani W, et al. Surviving sepsis campaign: International guidelines for management of sepsis and septic shock, 2016. Intensive Care Med 2017;43930:304-77.

7. Guan WJ, Ni ZY, Hu Y, et al. Clinical characteristics of coronavirus disease 2019 in China. N Engl J Med 2020;382:170820. doi:10.1056/NEJMoa2002032.

8. WHO. Report of the WHO-China Joint Mission on Coronavirus Disease 2019 (COVID-19). Accessed on: 20 th June 2020. Available from: https://www.who.int/docs/defaultsource/coronaviruse/who-china-joint-mission-on-covid-19final-report.pdf

9. Wu Z, McGoogan JM. Characteristics of and important lessons from the Coronavirus disease 2019 (COVID-19) outbreak in China: Summary of a report of 72314 cases from the Chinese Center for Disease Control and Prevention. JAMA 2020;323:1239-124.

10. Richardson S, Hirsch JS, Narasimhan M, et al. Presenting characteristics, comorbidities, and outcomes among 5700 patients hospitalized with COVID-19 in the New York City area. JAMA 2020;323:2052-9.

11. Ministry of Home Affairs, Government of India. Population census of India. Accessed: on $20^{\text {th }}$ June 2020. Available from: https://censusindia.gov.in/Census_And_You/age_structure_an d_marital_status.aspx

12. Xie J, Yong Z, Guan X, et al. Clinical characteristics of patients who died of Coronavirus disease 2019 in China. JAMA Netw Open 2020;3:e205619.

13. Zheng Z, Peng F, Xu B, et al. Risk factors of critical \& mortal COVID-19 cases: A systematic literature review and metaanalysis. J Infect 2020;81:e16-25.

14. Ferreira M, Blin T, Collercandy N, et al. Critically ill SARSCoV-2-infected patients are not stratified as sepsis by the qSOFA. Ann Intensive Care 2020;10:43.

15. Motta I, Centis R, D'Ambrosio L, et al. Tuberculosis, COVID19 and migrants: Preliminary analysis of deaths occurring in 69 patients from two cohorts. Pulmonology 2020;26:233-40. 